\title{
The effect of stimulus familiarization procedure on paired-associate verbal learning
}

WALLACE J. ORLOWSKY ${ }^{1}$ AKD JOHN F. WALSH

FORDHAM UNIVERSITY

Ss were familiarized with stimulus words under either of two conditions: aimed at differentiating stimuli or creating associations to them. When the stimuli were used in a pairedassociate task, Ss who attended to differentiating stimulus properties performed better than Ss whoformed associations to the stimuli or Ss who had no pretraining. Ss who formed associations did not differ in learning from Ss without pretraining.

Several recent studies have reemphasized the importance of the stimulus term in paired-associate (PA) learning. If knowledge of the stimuli is an important facet of PA learning, it would be expected that prior acquaintance with the stimulus members of $S-R$ pairs should facilitate learning of the pairs. However, the empirical data on stimulus familiarization are not consistent with this expectation.

Some investigators concluded that familiarization with stimuli had no effect on PA acquisition (Bailey \& Jeffrey, 1958; Mandler \& Campbell, 1957). Other studies have obtained the expected facilitation of PA learning after stimulus familiarization (Cieutat, 1960; Gannon \& Noble, 1961). Still other data suggest that stimulus familiarization inhibited PA acquisition (Sheffield, 1946; Underwood \& Schulz, 1960).

It has been shown that differences in familiarization procedure (Gillooly, 1965) or learning material (Runquist \& Freeman, 1960) can influence the efficacy of stimulus familiarization. A factor which might account for the success of some familiarization techniques and the failure of others is the orientation of the S. Specifically, this study investigated two possible ways in which the $S$ might react during familiarization trials.

It is generally agreed that successful PA learning depends in part on adequate stimulus differentiation or discrimination. Therefore, successful stimulus familiarization should orient $\mathrm{S}$ to differentiate the stimuli (Kurtz, 1955). Moreover, it is widely agreed that learning new responses to old stimuli produces negative transfer (Battig, 1966). Therefore, stimulus familiarization procedures should not allow $S$ to form associations (responses) to the stimuli. Such associations might compete with the responses to be learned in the test task. The extent to which different familiarization procedures fulfill these prerequisites should influence their effectiveness in facilitating PA learning.

Subjects

Forty-five male undergraduate students were randomly assigned to three groups of 15 each.

\section{Apparafus and Materials}

All materials were presented on an electronic memory drum (Wichita Model 241). The learning material was two-syllable nouns chosen randomly from the 20-40 frequency count in the general usage classification of the Thorndike-Lorge (1944) listing. There were 10 stimulus and 10 response words.

\section{Procedure}

There were three experimental conditions.

(1) Control. The Ss in this group received no stimulus pretraining but proceeded directly to the PA learning task after initial warmup trials.

(2) Attention. This familiarization procedure was intended to emphasize the differences between stimuli by focusing attention on a discriminating property, viz., spelling. The 10 stimuli were randomized in groups of 10 through 20 random orders for a total of 200 presentations. The first presentation contained the 10 stimuli correctly spelled, and $\mathbf{S}$ simply read them aloud. Thereafter, within each presentation of the 10 words, two were misspelled and appeared at random with the restriction that no word be misspelled more than four times. Misspellings involved only rearrangement of the letters of the word and never correctly spelled another word. Each time a word was misspelled a different arrangement of letters was used. $S$ was instructed that he would see the 10 words of the first trial many times in random order and that some would be misspelled. He was to look at each word and merely say "right" or "wrong" "each time, depending on the spelling. Exposure time for each word was $0.20 \mathrm{sec}$ with a blank time of $3.00 \mathrm{sec}$ between stimuli.

(3) Association. This group received exactly the same amount of familiarization with the same words in the same order as did the Attention group. However, none of the words was misspelled. The procedure for this group was aimed at making $S$ associate competing responses with the stimuli during familiarization. $S$ was allowed to read the words on the first presentation and thereafter instructed to respond with the first word which came to mind every time he saw a stimulus word. Emphasis was placed on the response merely being the first impression rather than attempting originality on each presentation of a word or repeating previous associations.

After the familiarization trials, all Ss were given the PA test. The 10 stimuli were paired with 10 response words and Ss were given standard PA instructions. The stimulus was exposed for $1.00 \mathrm{sec}$ followed by $0.50 \mathrm{sec}$ blank time before $1.00 \mathrm{sec}$ exposure of the $S-R$ pair. Thus, the effective anticipation interval was $1.50 \mathrm{sec}$. All Ss were run to a criterion of 12 trials and errors were recorded for each trial.

Results

All analyses were on the total number of errors for 


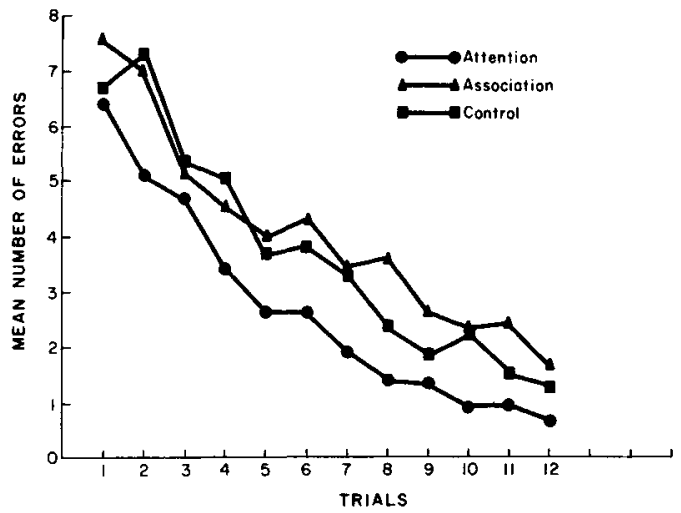

Fig. 1. Mean number of errors for each leaming trial made by the three experimental groups.

the $15 \mathrm{Ss}$ in each group. The Attention group made fewest errors followed by the Control group, with the Association group making the most errors. Based on t tests, the Attention group performed significantly better than both the Association and Control groups at the .05 level. The latter two groups did not differ significantly from each other. Figure 1 shows that these relations among groups are consistent on a trial by trial basis. Thus, compared to no familiarization, attending to stimulus spelling during familiarization facilitated PA learning, whereas associating to stimuli during familiarization had no effect or a slight trend toward inhibition of PA learning.

Discussion

It was hypothesized that the behavior of the $S$ during familiarization trials might significantly affect the results of stimulus familiarization. Specifically, the notion was that attending to differentiating stimulus characteristics would facilitate PA learning, while formation of associations to the stimuli would inhibit the PA acquisition. In general, the data are supportive when two differently instructed groups are compared to a group without familiarization, though the trend toward inhibition in the Association group is not significant.

Given that differentiation of stimuli is an important aspect of PA learning, stimulus familiarization will facilitate such learning if it encourages differentiation. Distinguishing features of verbal stimuli might be their spelling, pronunciation, or general configuration (especially with very short exposures). Pretraining techniques which have been successful in facilitating PA learning can, in general, be shown to emphasize such cues (Gillooly, 1965; Kurtz, 1955). However, to be successful a familiarization technique must also avoid the possibility of $S$ attaching competing responses to the stimuli. The common procedure of learning specific responses (verbal or motor) to stimuli during familiarization (Sheffield, 1946; Underwood \& Schulz, 1960) probably does produce some differentiation (necessary to attach unique responses). But, this procedure sets up competing responses, similar to the A-B, A-C negative transfer paradigm. Even in cases where competing responses are not directly learned through instructions, S may still associate to the stimuli on his own. Since in most cases demonstrating inhibitory influences of stimulus familiarization the effects were not significant (as in this study), the benefits of differentiation by learning responses are probably canceled by the detriment of response competition, to produce no effect. Generally, familiarization procedures which produced no effect on PA learning either did not demand attention to discriminating cues or set up a conflict situation as described above. It might also be true that some procedures are facilitating simply because they do not allow formation of competing responses (e.g., very brief exposure times (Gannon \& Noble, 1961)).

In summary, stimulus familiarization cannot be assessed without regard to differences in familiarization techniques. Specifically, the way in which $S$ is oriented (either by instruction or not) to react to the stimuli during familiarization can significantly influence the effect of familiarization on the PA learning task.

\section{References}

Bailey, Joan H., \& Jeffrey, W. E. Response strength and association value in stimulus predifferentiation. Psychol. Rep., 1958, 4, 715-721.

Battig, W. F. A shift from "negative" to "positive" transfer under the A-C paradigm with increased number of C-D control pairs in a mixed list. Psychon. Sci., 1966, 4, 421-422.

Cieutat, V. J. Differential familiarity with stimulus and response in paired-associate learning, Percept. mot. Skills, 1960, 11, 269-275.

Gannon, D. R., \& Noble, C. E. Familiarization ( $n^{*}$ ) as a stimulus factor in paired-associate verbal learning. J. exp. Psychol., $1961,62,14-23$.

Gillooly, w. B. The effects of familiarization on associative latency. Psychon. Sc ., 1965, 3, 235-236.

Kurtz, K. H. Discrimination of complex stimuli: The relationship of training and test stimuli in transfer of discrimination. $J$. exp. Psychol., 1955, 50, 283-292.

Mandler, G., \& Campbell, E. H. Effect of $\bullet$ variation in associative frequency of stimulus and response members on paired-associate learning. J. exp. Psychol., 1957, 54, 269-273.

Runquist, W. N., \& Freeman, Madelyn. Roles of association value and syllable familiarization in verbal discrimination learning. J. exp. Psychol., 1960, 59, 396-401.

Sheffield, F. D. The role of meaningfulness of stimulus and response in verbal learning. Unpublished doctoral dissertation, Yale University, 1946.

Thomdike, E. L., \& Lorge, J. The teacher's word book of 30,000 words. New York: Teachers College, Columbia University, 1944.

Underwood, B. J., \& Schulz, R. W. Meaningfulness and verbal learning. Philadelphia: Lippincott, 1960.

Note

1. Now at New York State Psychiatric Institute. 